W. R. Fulton

\title{
Audio-Visual Competence and Teacher Preparation
}

$\mathrm{T}$

$\mathrm{HE}$ preparation of more and better qualified teachers includes preparing teachers not only to teach more concepts, but to teach them more effectively. Moreover, these teachers must be prepared to manage classes with greatly increased enrollments and to teach in an environment that is beset with many external influences, some of which might be made useful to education. One of the most important of these influences is the wide use of communicative media by noneducational agencies. The effectiveness of such media in communicating ideas is indicated by their continued and expanded use by industry and other agencies outside of education. How, then, can they be converted to improve communication in the formalized educational process? Obviously, this is a responsibility of teacher education institutions in their preparation of teachers.

The preparation of teachers to teach more concepts effectively within a culture that has become as complex as ours requires the development of many competences, among which are those relating to communicative media, more commonly called audio-visual materials. Unfortunately, the development of audiovisual competence is too frequently overlooked or is given too little attention in teacher education programs.

Yet it is evident that the methods and materials of yesterday are as inadequate for present and future needs in education as they would be in science and industry. This is not to suggest that communicative media and techniques by themselves are panaceas. But it is clear that the job cannot be done without them.

Although today's communicative media and techniques are in some cases different from those of yesterday, the advocacy of their use is not new. Long before teacher education institutions began including preparation in the use of such media, under the term audio-visual education, educators were aware of their value. Much in the writings of Comenius, Pestalozzi, Rousseau, and Froebel would, if read today, sound similar to the most authoritative textbooks in audio-visual education.

More recently, attempts have been made to stimulate teacher preparation in the use of instructional materials through legislation, revision of college curriculums, and a variety of inservice devices. In 1934 the commonwealth of Pennsylvania enacted legislation requiring all applicants for a permanent teaching certificate to have "an approved course in visual and sensory techniques." California has had a similar requirement since 1946. At about this time the American Council on Education further stimulated attention to audio-visual education by publishing a statement on its meaning that spelled out teacher competences in this area. ${ }^{1}$ Since that time a number of teacher education institutions have required an audio-visual course for

${ }^{1}$ Elizabeth Goudy Noel and J. Paul Leonard, Foundations for Teacher Education in AudioVisual Instruction (Washington, D. C.: American Council on Education, 1947) p. 1-3.

Dr. Fulton is associate professor of education, University of Oklahoma, Norman. 
graduation. Today nearly every audiovisual center in the country is actively engaged in some kind of audio-visual inservice activity.

Despite such efforts as these, the rather conclusive body of research produced over the last 40 years pointing to the values derived from the proper use of the audio-visual materials, and our knowledge of the audio-visual competences teachers should possess, many teachers today are not very well prepared to take advantage of audio-visual devices and materials that are generally available to them. A survey made by the National Education Association in 1957 showed that about 50 per cent of the 5,602 American teachers returning their questionnaire did not feel confident in their ability to use audio-visual equipment and materials. ${ }^{2}$ A University of Wisconsin study reports that a great proportion of the secondary-school teachers questioned did not know what a filmstrip projector was, and that many teachers who used audio-visual materials felt they had not been prepared to use them effectively. ${ }^{3}$

Such data should stimulate a greater concern among those responsible for teacher education programs for more systematic efforts in providing opportunities for preservice teachers to develop competence in the use of audio-visual materials. During the last few years teacher education institutions and professional organizations, particularly the NEA's National Commission on Teacher Education and Professional Standards, have given much attention to the identification of competences needed by teach-

2 National Education Association, Research Division, "The Status of the American PublicSchool Teacher," NEA Research Bulletin 35:1:30; 1957.

'Frederick A. White, One Study of the University of Wisconsin's School of Education Progress in Providing Competency in Selecting Audio-Visuai Methods (Unpublished Ph.D. Thesis, School of Education, University of Wisconsin, 1952). ers. A perusal of most lists of teacher competences reveals that specific competences in the area of methods and materials are seldom mentioned. More recently, however, a rather well-defined list of audio-visual competences was formulated by the Teacher Education Committee of the Department of AudioVisual Instruction, NEA. ${ }^{4}$

This list contains such general areas of competence as (1) proficiency in selection and evaluation of materials; (2) pro ficiency in the utilization of appropriate instructional materials; (3) proficiency in production of simple instructional materials; and (4) proficiency in the preparation and use of physical facilities.

Assuming that the audio-visual competences included in the above list are valid and necessary for effective teaching, the crucial issue is how the present teacher education program can be adjusted to insure optimum opportunities for preservice teachers to achieve them. A group of audio-visual leaders at the 1958 Okoboji Conference proposed some methods of doing this. ${ }^{5}$

\section{Methods of Achieving Audio-Visual Competence}

The most common method of providing opportunities for preservice teachers to achieve audio-visual competence is to add a course in audio-visual education and require all to take it. This has been done in a good many institutions with varying degrees of effectiveness. There is some evidence that this method is not the complete answer to the problem because of academic and scheduling diffculties and the difficulty of providing adequate laboratory experience necessary to develop the skills relating to audiovisual competence.

${ }^{4}$ W. R. Fulton and Frederick A. White, "What Constitutes Teacher Competence in Audio-Visual Communication?" Phi Delta Kappan 40:158-60; January 1959.

" "The Okoboji Report," Audio-Visual Instruction 4:4-6; January 1959. 
Another way of providing for the achievement of audio-visual competence is to integrate audio-visual methods and materials with the traditional methods courses and other professional education courses. Theoretically, this is a realistic approach and one which should reach all prospective teachers. It provides real opportunity for the prospective teacher to make meaningful use of audio-visual materials in connection with laboratory assignments relating to methods and subject matter. It has serious limitations, however. Often there is too little time to cover all competences. Some who teach these courses lack audio-visual competence themselves. Such a plan normally works best with a team approach and this is not always practical at the college level.

A third way of providing opportunities for preservice teachers to achieve audio-visual competence is through a strictly laboratory approach. This requires that all students devote sufficient time in the audio-visual laboratory to complete projects designed to produce competences applicable to their needs. The success of this approach is contingent upon acceptance and participation by the entire faculty, the requirement that all students complete the program, the services of professionally qualified laboratory assistants, and a systematic method of evaluating the student's accomplishments.

Because of the complexity of problems associated with developing audio-visual competences, many of which are closely related to other teacher competences, and because of the existence of a variety of local problems stemming from the different patterns of teacher education, it seems apparent that teacher education institutions, particularly those that are multi-purpose, should embark upon an intensive program designed to develop in every prospective teacher adequate audio-visual competence. Such a pro- gram might employ a combination of three or four methods: (1) the completion of a formal audio-visual course; (2) project participation in methods courses combined with laboratory assignments; (3) experience in an audiovisual laboratory with appropriate space, materials, equipment, and adequate personnel; and (4) liberal use of appropriate materials by teachers of the professional courses in their day-to-day instruction. Much use of students should be made in the latter, both in selection and utilization practices, and in the operation of projection equipment.

Regardless of the manner in which an institution provides audio-visual learning opportunities, the student should be able to demonstrate proficiency in each audiovisual competence. This means that both the faculty and the students must clearly understand the precise competences to be demonstrated. Such a program would presume a requirement that all students present a certificate of audio-visual proficiency to the director of student teaching before being admitted to student teaching or before being granted a teaching certificate.

\section{Determining Audio-Visual Competence}

The determination of such competence should be made by the professor and staff in charge of the audio-visual laboratory from an approved list of audiovisual competences including (1) a working point of view with respect to audiovisual materials; (2) knowledge about and experience in locating, selecting, evaluating, and using all kinds of audiovisual materials; (3) ability to prepare some of the simpler types of audio-visual materials; and (4) skill in the operation of common types of audio-visual equipment.

Students should be made aware of the specific competences they are expected to demonstrate and the tasks they should perform in achieving them. They should 
also be familiar with opportunities available to them for their achievement.

At best, information for determining audio-visual competence is highly subjective. Nevertheless, it is paramount that competence in each area be evaluated. Due to the diversity of programs among institutions, it is necessary to develop evaluative instruments to fit the local situation in order that competence in each area may be evaluated. The following is a suggested guide for doing this.

Competence in the selection and evaluation of materials, requires that the prospective teacher possess a working point of view regarding audio-visual materials by acquiring a knowledge about all types of mass-communication media and by developing skills in locating, selecting, and evaluating such media.

Some ways of obtaining information which may be useful in determining whether students have developed this competence are as follows:

1. Have students match pictures of all types of audio-visual equipment and materials with a list of names of such media.

2. Have students match names of materials with a list of characteristics peculiar to certain types of materials.

3. Have students match pictures of materials with a list of purposes to be achieved.

4. Have students answer multiplechoice items relating to problems to which certain materials are suitable.

5. Have students answer problem-solving questions relating to selection of specific materials for stated purposes.

6. Have students answer problem-solving questions relating to the use of the most appropriate materials for stated purposes.

7. Have students answer multiplechoice items relating to the evaluation of appropriate materials in terms of stated purposes.

8. Describe a problem and have stu- dents suggest the most appropriate material to achieve stated purposes.

9. Have students answer problem-solving questions about location of film libraries and other materials that may be located inside or outside the school system. (This method may also be used to determine whether the students have knowledge of procedures for obtaining materials from various sources.)

In determining whether prospective teachers have attained proficiency in the utilization of appropriate instructional materials, the evaluator should recognize that the teacher should have a functional knowledge of techniques of utilization of all types of educational media, and. that this might be facilitated through an understanding of the basic philosophy underlying the successful use of educational media; an understanding of the role of methods and materials in the instructional process; and an appreciation of the advantages of a wide range of instructional materials.

Some methods of obtaining information for evaluating the student's competence in this area are:

1. Have students view and write a review with emphasis on the role of materials in learning of such films as Accent on Learning, Bringing the World Into the Classroom, New Tools for Learning, and Film Research in Learning.

2. Have students answer multiplechoice items relating to values derived from correct use of films in terms of purposes for which films are suited.

3. Have students list the principal steps for good use of a motion picture film for stated purposes.

4. Have students view and write a review of such films as Using the Classroom Film and Chalkboard Utilization.

5. Have students develop a unit of work which includes the use of such aids and materials as films, chalkboard devices, feltboard materials, bulletin-board materials, 3-D materials, and the field trip. 
In determining whether prospective teachers are proficient in the production of simple instructional materials, the student should be required to demonstrate an ability to prepare some of the simpler types of audio-visual materials.

One way of obtaining information on which to determine the student's competence in this area is to administer a performance test in which the student demonstrates knowledge of principles and skill in preparing such items as bulletinboard displays, feltboards, handmade slides, mounted study prints, and tape recordings.

In determining whether prospective teachers possess proficiency in the preparation and use of physical facilities, the evaluator should require the student to demonstrate skill in arranging the physical facilities for using audio-visual materials, and to possess the ability to manipulate and arrange audio-visual equipment and materials for classroom use. Again, a desirable way of obtaining information for the evaluation of this competence is to use performance tests in which the student demonstrates a knowledge of, and skill in placement of, screen, speaker, and seats for optimum viewing and hearing; tests in which the student demonstrates ability to operate such equipment as the motion-picture projector, filmstrip projector, slide projector, opaque projector, and tape recorder; and opportunities for the student to demonstrate abilities to construct mock-ups and models.

Another important element necessary for optimum results in developing audiovisual competence is the provision for adequate physical facilities. Films, filmstrips, projection equipment, and other pertinent materials and equipment must be readily available and easily obtainable. Also, adequate classroom projection facilities and laboratory space and equipment must be readily available.
Research evidence indicates that we know much more about what we should be doing with modern communicative media in education than we are actually doing. It is also very likely that one of the principal reasons for this is that teachers are not well enough prepared to feel secure in the use of appropriate media. Obviously, if we are to do what we should, teachers must be more adequately prepared.

The manner in which this is done, whether it is through a well designed audio-visual course, through integration of audio-visual materials with traditional methods courses, through a carefully planned laboratory approach, or through a combination of these, is relatively unimportant if adequate student evaluation is made. A well-planned, comprehensive program for evaluating the extent to which prospective teachers have achieved competence in the use of communicative media will greatly enhance their chances of achieving such competence.

Such a plan should be equally shared by both faculty and students. Each faculty member should be continuously aware of the needs of the student to the extent that ample opportunities are provided in each course for each student to learn about and make use of communicative media. Also, each student should be continuously aware of the competences he must achieve and thus be stimulated to achieve them, even if it means going beyond formalized opportunities.

Although such a program has its administrative difficulties, it is administratively and economically feasible. The urgency for preparing teachers to make the fullest use of modern communicative media makes it incumbent upon all teacher education institutions to formulate a systematic and comprehensive program of developing teacher competence in the use of such media. 